\title{
EFFECT OF YOGA EXERCISE ON METABOLIC AND HOMEOSTATIC PARAMETERS OF INSULIN RESISTANCE
}

\author{
Pastucha D. ${ }^{1}$, Filipcikova R. ${ }^{2}$, Cajka V. ${ }^{1}$, Horakova D. ${ }^{3}$, Radova L. ${ }^{4}$, Reich P. ${ }^{5}$, \\ Sovova E., 1
}

\footnotetext{
${ }^{1}$ Department of Sports and Exercise Medicine, Faculty of Medicine and Dentistry, Palacky University Olomouc, Tř. Svobody 8, 771 26, Olomouc, Czech Republic.

${ }^{2}$ Department of Anatomy, Faculty of Medicine and Dentistry, Palacky University Olomouc, Tř. Svobody 8 , 771 26, Olomouc, Czech Republic.

${ }^{3}$ Department of Preventive Medicine, Faculty of Medicine and Dentistry, Palacky University Olomouc, 771 26, Olomouc, Czech Republic.

${ }^{4}$ Laboratory of Experimental Medicine, Institute of Molecular and Translational Medicine, Faculty of Medicine and Dentristry, Palacky University Olomouc, 771 26, Olomouc, Czech Republic.

${ }^{5}$ Department of Sports, Faculty of Physical Culture, Palacky University Olomouc, Tŕ. Míru 115
}

\section{A b s t r a c t}

The aim of this study is to assess the effect of yoga exercise on the anthropometric parameters and metabolic parameters in individuals regularly exercising yoga as well as to assess the possible impact on cardiovascular risk prevention. The study sample composed of two groups: A (57 healthy control) and B (61 subjects exercised yoga). For each group were measured: blood pressure, body mass index (BMI) and laboratory values of total cholesterol, triglycerides, high density lipoproteins (HDL) and low density lipoproteins (LDL) cholesterol, glycaemia and insulinemia, homeostasis model assessment of insulin resistance (HOMA-IR) and quantitative insulin-sensitivity check index (QUICKI). BMI was significantly lower $(p=0.005923)$ in the group B (yoga). We found an impact of yoga on the homeostatic indices HOMA-IR and QUICKI and it mens significantly lower value of systolic blood pressure $(p=0.043543)$ and LDL cholesterol levels $(p=0.008714)$.

Based on these outcomes, we consider yoga to be a suitable physical activity to prevent cardiovascular diseases.

Key words: yoga, insuline resistance, cardiovascular diseases, HOMA-IR, QUICKI.

\section{INTRODUCTION}

Owing to the intensive interdisciplinary co-operation between the respective medical fields the mortality rate from cardiovascular diseases has been significantly reduced. However, cardiovascular diseases remain the most frequent cause of death in adults, account for most sick leaves, incur significant financial burden from treatment and prevention, and continue to represent a major health and social-economic problem not only for the developed countries (1).

For a very long time the causality between some nosological features, such as hypertension, obesity, diabetes mellitus (DM), dyslipidemia and some others, and the development of cardiovascular diseases has been known. Vascular disease is here the main cause of morbidity and mortality, and accelerated atherosclerosis is responsible for about $80 \%$ of mortality and for about $75 \%$ of hospitalizations (2). The cost of cardiovascular diseases in European Union is estimated to be as high as 169 billion Euro early (3). There is a need for efficient primary prevention that specifically focuses on the risk factors $(\mathrm{RF})$ influencing the onset of such diseases. The most significant role here

Address for correspond e n c e:

Dalibor Pastucha, MD, Ph.D, MBA, Klinika tělovýchovného lékařství a kardiovaskulární rehabilitace FN a LF UP Olomouc, I.P.Pavlova 6, Olomouc, 775 20, Czech Republic

Phone: +420 58844 3590; e-mail: Dalibor.Pastucha@fnol.cz 
is assigned to the risk factors linked with the metabolic syndrome (MS). The impact of changes in diet and, in particular, in the physical activities has been demonstrated by a number of studies. For example, Ivy correlated the relationships between hypokinesia under genetic pre-disposition with the development of insulin resistance (4).

Regarding the strong influence of psychosocial factors on the development of MS and cardiovascular diseases (CVD), on the key role of activation of sympathetics in the pathogenesis of insulin-resistant conditions, on the ability of regeneration and restoration of changes resulting from MS, the mind-body therapy represents a considerable potential in the prevention and treatment of cardiovascular diseases $(5,6,7)$. In this respect, yoga enjoys a special status. It is the oldest known system of personal development covering the body, mind and spirit. There are only a few studies in international literature documenting the positive impact of regular yoga exercises on the CVD RF. The studies demonstrate that regular yoga exercises regulates arterial hypertension and improves cardiac performance, positively affects insulin resistance, abdominal obesity and improves type 2 diabetes mellitus, normalizes lipid profile, modifies coagulopathy and oxidation stress through balancing the sympathetic and parasympathetic tonus, positively affects certain anthropometric parameters and improves many other clinical parameters $(8,9,11)$. Also yoga has a potential impact on posture and stability control which is a process of maintaining balance and position of the body and its parts in a constantly changing environment. It is an important regulatory mechanism of the body, because it precedes movement, is upon the completion of which this system tries to maintain the body position (10).

The objective of this study is to assess the effect of yoga exercise on the anthropometric parameters : body mass index (BMI), metabolic parameters (glycaemia, insulinemia, LDL and HDL cholesterol,) and the homeostatic indices homeostasis model assessment of insulin resistance (HOMA-IR) and quantitative insulin-sensitivity check index (QUICKI) in individuals regularly exercising yoga for more than 1 year and to compare these parameters with the standard population without any apparent signs of insulin resistance.

\section{SUBJECTS AND METHODS}

In present study the subjects were divided in two independent groups. All subjects signed an informed consent prior to their entry into the study.

Group A contained 57 biological sample of the population subjects ( 29 women, 18 men, average age 50.93 SD 9.58) without clinical or metabolic signs of insulin resistance and the subjects were selected randomly out of a larger set of patients monitored by practitioners to ensure the study groups are consistent in terms of age and sex. This group included subjects who have not been treated yet for any chronic disease; however, their lab results subsequently showed deviations from physiological values.

Group B comprised 61 subjects ( 43 women and 18 men, average age 48.6 SD 11.6) who regularly, twice a week, exercised yoga for longer than 1 year.

The subjects in both groups were not on any special diet and observed their regular eating habits.

For each subject, the following parameters were measured: blood pressure, BMI and laboratory values of total cholesterol, triglycerides, HDL and LDL cholesterol, glycaemia and insulinemia. The values of glucose and insulin concentration were used to calculate HOMA-IR and QUICKI.

The HOMA- IR was calculated according to the homeostatic mode as $(12,13,14)$ :

HOMA IR = insulin fasting $(\mathrm{IU} / \mathrm{ml}) \times$ glycaemia fasting $(\mathrm{mmol} / \mathrm{l}) / 22.5$. 
QUICKI was calculated according to formula:

QUICKI $=1 /$ [log insulin fasting $(\mathrm{IU} / \mathrm{ml})+\log$ glycaemia fasting $(\mathrm{mmol} / \mathrm{l}) \times 18.182$

Statistical evaluation was done using the programme Statistics version 6.0 for analysis of the means, medians and standard deviations. T-test was calculated to determine statistical significance $(\mathrm{p}<0.05)$ in clinical and biochemical characteristics.

\section{RESULTS}

We have demonstrated statistically lower values of glycaemia $(p=0.017164)$ and insulinemia $\left(\mathrm{p}<10^{-6}\right)$ in the group of individuals exercising yoga for more than 1 year. We have also demonstrated a statistically significant difference in values of homeostatic indices HOMA-IR (decrease) and QUICKI (elevation) in a group of individuals exercising yoga $\left(\mathrm{p}<10^{-6}\right)$. (Table 1,2$)$.

Table 1 Results of examination in the groups A (controls) and B (yoga)

\begin{tabular}{|c|c|c|c|c|c|c|c|c|c|}
\hline & $\mathrm{N}$ & \multicolumn{3}{|c|}{$95 \%$} & \multirow{2}{*}{$\frac{\text { Median }}{120.00}$} & \multirow{2}{*}{$\frac{\text { Min }}{90.00}$} & \multirow{2}{*}{$\frac{\text { Max }}{160.00}$} & \multirow{2}{*}{$\frac{\mathrm{SD}}{18.61}$} \\
\hline \multirow{10}{*}{ 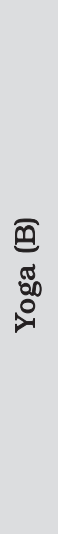 } & SYSTOL BP & 61 & 118.68 & 113.92 & 123.45 & & & & \\
\hline & DIASTOL BP & 61 & 74.75 & 71.83 & 77.67 & 80.00 & 60.00 & 120.00 & 11.4 \\
\hline & GLY (mmol/l) & 61 & 5.02 & 4.86 & 5.19 & 4.90 & 4.10 & 8.80 & 0.65 \\
\hline & HDL (mmol/l) & 61 & 1.60 & 1.50 & 1.70 & 1.52 & 0.82 & 2.95 & 0.39 \\
\hline & LDL (mmol/l) & 61 & 3.12 & 2.90 & 3.33 & 3.07 & 1.79 & 5.87 & 0.83 \\
\hline & BMI $\left(\mathrm{kg} / \mathrm{m}^{2}\right)$ & 61 & 23.11 & 22.32 & 23.90 & 22.70 & 17.40 & 30.90 & 3.08 \\
\hline & INZULIN (mlU/1) & 61 & 4.53 & 3.66 & 5.40 & 3.20 & 2.00 & 19.80 & 3.39 \\
\hline & Quicki & 61 & 0.40 & 0.38 & 0.41 & 0.39 & 0.30 & 0.46 & 0.04 \\
\hline & HOMA_IR & 61 & 1.03 & 0.81 & 1.24 & 0.78 & 0.36 & 4.92 & 0.84 \\
\hline & $\begin{array}{l}\text { Age } \\
\text { at examination }\end{array}$ & 61 & 48.62 & 45.65 & 51.59 & 48.00 & 26.00 & 68.00 & 11.60 \\
\hline \multirow{10}{*}{ 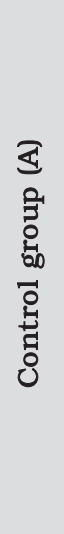 } & SYSTOL & 57 & 125.08 & 121.28 & 128.88 & 125.00 & 95.00 & 170.00 & 14.31 \\
\hline & DIASTOL & 57 & 76.31 & 73.66 & 78.96 & 75.00 & 60.00 & 110.00 & 9.97 \\
\hline & GLY (mmol/1) & 57 & 5.18 & 5.06 & 5.31 & 5.10 & 4.30 & 6.40 & 0.45 \\
\hline & HDL (mmol/l) & 57 & 1.68 & 1.59 & 1.77 & 1.70 & 1.08 & 2.47 & 0.34 \\
\hline & LDL (mmol/l) & 57 & 3.23 & 3.07 & 3.38 & 3.30 & 1.30 & 4.26 & 0.58 \\
\hline & BMI (kg/m2) & 57 & 24.42 & 23.75 & 25.09 & 24.44 & 19.03 & 29.32 & 2.52 \\
\hline & INZULIN (mlU/l) & 57 & 8.57 & 7.34 & 9.80 & 7.70 & 2.20 & 22.10 & 4.59 \\
\hline & Quicki & 57 & 0.35 & 0.34 & 0.36 & 0.34 & 0.29 & 0,44 & 0.03 \\
\hline & HOMA_IR & 57 & 2.01 & 1.69 & 2.33 & 1.81 & 0.43 & 5.83 & 1.19 \\
\hline & $\begin{array}{l}\text { Age } \\
\text { at examination }\end{array}$ & 57 & 50.92 & 48.38 & 53.47 & 54.00 & 22.00 & 63.00 & 9.58 \\
\hline
\end{tabular}

SYSTOL BP- systolic blood pressure, DIASTOL BP- diastolic blood pressure, GLY- glycaemia, HDL- high density lipoprotein, LDL low density lipoprotein, BMI -Body Mass Index 
Table 2 Statistical significance of individual parameters in A and B

\begin{tabular}{|l|ccc|}
\hline & N (A) & N (B) & $\begin{array}{c}\text { p-value } \\
\text { (Mann-Whitney) }\end{array}$ \\
\hline SYSTOL BP & 57 & 61 & 0.029212 \\
DIASTOL BP & 57 & 61 & 0.411358 \\
GLY & 57 & 61 & 0.017164 \\
HDL & 57 & 61 & 0.182376 \\
LDL & 57 & 61 & 0.146395 \\
BMI & 57 & 61 & 0.005923 \\
INZULIN & 57 & 61 & $\mathrm{p}<10^{-6}$ \\
Quicki & 57 & 61 & $\mathrm{p}<10^{-6}$ \\
HOMA_IR & 57 & 61 & $\mathrm{p}<10^{-6}$ \\
AGE & 57 & 61 & 0.252377 \\
\hline
\end{tabular}

SYSTOL BP- systolic blood pressure, DIASTOL BP- diastolic blood pressure, GLY- glycaemia, HDL- high density lipoprotend, LDL low density lipoprotein, BMI -Body Mass Index

Group B (yoga) demonstrated statistically significantly lower value of systolic blood pressure, value of serum insulin, both homeostatic indices HOMA-IR and QUICKI, BMI value and serum glycaemia.

Comparing the individual parameters in both groups using sex as a parameter of comparison, in men, group B- yoga subjects, was significantly lower BMI, systolic blood pressure, insulinemia, LDL cholesterol and both homeostatic indices HOMA-IR and QUICKI.

Comparing women from both groups A and B we found in group B only a statistically significantly lower insulinemia and significant difference in both homeostatic indices HOMA-IR and QUICKI. We have not found significant difference in systolic blood pressure, LDL cholesterol and BMI as in the group of men (Table 3).

Table 3 Comparison of statistical significance of individual parameters in A and B; gender is the parameter for comparison

\begin{tabular}{|l|ccc|ccc|}
\hline & \multicolumn{3}{|c|}{ Men } & \multicolumn{3}{c|}{ Women } \\
& N (A) & N (B) & $\begin{array}{c}\text { p-value } \\
\text { (Mann-Whitney) }\end{array}$ & N (A) & N (B) & $\begin{array}{c}\text { p-value } \\
\text { (Mann-Whitney) }\end{array}$ \\
\hline SYSTOL BP & 18 & 18 & 0.043543 & 39 & 43 & 0.218130 \\
DIASTOL BP & 18 & 18 & 0.742798 & 39 & 43 & 0.287289 \\
GLY & 18 & 18 & 0.050859 & 39 & 43 & 0.121413 \\
HDL & 18 & 18 & 0.481230 & 39 & 43 & 0.517727 \\
LDL & 18 & 18 & 0.008714 & 39 & 43 & 0.904451 \\
BMI & 18 & 18 & 0.007105 & 39 & 43 & 0.068615 \\
INZULIN & 18 & 18 & p<10-6 & 39 & 43 & 0.000300 \\
Guicki & 18 & 18 & p<10-6 & 39 & 43 & 0.000336 \\
HOMA_IR & 18 & 18 & p<10-6 & 39 & 43 & 0.000336 \\
\hline
\end{tabular}

SYSTOL BP- systolic blood pressure, DIASTOL BP- diastolic blood pressure, GLY- glycaemia, HDL- high density lipoprotein, LDL low density lipoprotein, BMI -Body Mass Index 


\section{DISCUSSION}

There is rather limited number of studies analysing the impact of yoga exercise on CVD RF. Most studies were carried out in Asia.

The results of our study confirmed the positive effect of regular exercise not only on the anthropometric parameters, where in the group of yoga men the BMI was significantly lower ( $p=0.005923)$, but also on the homeostatic indices HOMA-IR and QUICKI demonstrated a decrease in risk factors for CVD in patients who exercised yoga through reduction of glycaemia, cholesterol, triglycerides, improvement of subjective condition and the quality of life and reduction in blood pressure. They also demonstrated reduction in catecholamine levels, reduced sympathetic tonus and oxidation stress (15). Our study also demonstrates significantly lower value of systolic blood pressure in men $(\mathrm{p}=$ 0.043543). Therefore, it is possible to agree with the studies carried out by other authors that yoga exercise may be recommended as an efficient, non-pharmacological, safe and not so difficult way to significantly reduce hypertension, primarily in men $(9,16)$.

Simple fasting methods to measure insulin resistance, such as the homeostasis model assessment (HOMA-IR), and quantitative insulin sensitivity check index (QUICKI)

methods, have been widely promoted for studies, because of the possibility of evaluating insulin sensitivity from the levels of glycaemia and insulinaemia with the help of the homeostatic indices HOMA-IR and QUICKI which is for use in general practice $(17,18)$. The significant difference in the glycaemia level $(p=0.017164)$, insulinemia $\left(\mathrm{p}<10^{-6}\right)$ and homeostatic indices calculated based on these values HOMA-IR $\left(\mathrm{p}<10^{-6}\right)$ and QUICKI $\left(\mathrm{p}<10^{-6}\right)$ may be seen very positively as they indicate the protective effect of yoga exercise against the development of insulin resistance or metabolic syndrome. These results are in compliance with a similar monitoring by Bijani (2005), which demonstrated a decrease in glycaemia and adjustment of total cholesterol, LDL cholesterol and HDL cholesterol already after a 9-week yoga course (10).

Our study demonstrated a significant impact on LDL cholesterol levels $(p=0.008714)$ and BMI $(\mathrm{p}=0.007105)$ for men, in women the difference was not statistically significant. The possible explanation is, that men exercised more frequently and for more years than women.

We have demonstrated statistically lower values of glycaemia and insulinemia in the group of individuals exercising yoga for more than 1 year. We have also demonstrated a statistically significant difference in values of homeostatic indices HOMA-IR and QUICKI. Based on these outcomes we consider yoga could be a suitable physical activity and may be recommended as an efficient, non-pharmacological, safe and not so difficult ways to prevent cardiovascular diseases. On the other hand, the authors are aware of the fact that the positive effect of regular yoga exercise may also be influenced by a different diet and lifestyle of individuals regularly exercising yoga and they recommend to focus on further studies in this area.

\section{REFERENCES}

1. Ginter E., Simko V. (2010): Biased reporting on cardiovascular mortality in Europe. Bratisl. Lek. Listy. 111: 574

2. Murín J., Yaghy M. (2009): Diabetes and vascular diabetic disease. Vnitr. Lek. 55: 788-791

3. Turek P., Lietava J., Foltan V., Kosmalova V., Dukat A. (2010): Costs related to medical treatment for common cardiovascular risk factors. Bratisl. Lek. Listy (2010): 111: 535-540

4. Ivy JL. Muscle insulin resistance amended with exercise training: role of GLUT4 expression. Med Sci Sports Exerc. 2004 Jul; 36(7): 1207-11.

5. Svačina Š. a kol. (2006): Metabolický syndrom. TRITON, Praha 
6. Simková A., Bulas J., Murín J., Kozlíková K., Janiga I. (2010): Metabolic syndrome and aortic stiffness. Vnitr. Lek. 56: 1000-1004

7. Klimes I., Hrnciar J. (1995): The insulin resistance syndrome. Vnitr. Lek. 41:75

8. Innes K.E., Bourguignon C., Pylor A.G. (2005): Risk indices associated with the insulin resistance syndrome, cardiovascular disease, and possible protection with yoga: A systematic review. J. Am. Board. Fam. Med. 18: 491-519

9. Saptharishi L., Soudarssanane M., Thiruselvakumar D., Navasakthi D., Mathanraj S., Karthigeyan M., Sanhai A. (2009): Community-based randomized controlled trial of non-pharmacological interventions in prevention and control of hypertension among young adults. Indian. J. Community. Med. 34: 329-334

10. Bijlani R.L., Vempati R.P., Yadav R.K., Ray R.B., Gupta V., Sharma R., Mehta N., Mahapatra S.C. (2005): Brief but comprihensive lifestyle education program based on yoga reduces risk factors for cardiovascular disease and diabetes mellitus. J. Altern. Complement. Med. 11: 267-274

11. Molikova R., Bezdičkova M., Langova K., Holibka V., David O., Michalikova Z., Řehořova J. (2006): The relationship between morfological indicators of human body and posture. Biomed. Pap. Med. Fac. Univ. Palacky. Olomouc. Czech. Repub. 150: 261-265

12. Haffner S.M., Miettinen H., Stern M.P. (1997): The homeostasis model in the San Antonio heart study. Diabetes. Care. 20: 1087-1092

13. Matthews D.R., Hosker J.P., Rudenski A.S., Naylor B.A., Treacher D.F., Turner R.C. (1985): Homeostasis model assessment: Insulin resistance and -cell function from fasting plasma glucose nad insulin concentration in man. Diabetologia. 28: 412-419

14. Katz A., Nambi S.S., Mather K., Baron A.D., Follmann D.A., Sullivan G., Quon M.J. (2000): Quantitative insulin sensitivity check index a: simple, accurate method for assessing insulin sensitivity in humans. J. Clin. Endocrinol. Metab. 85: 2402-2410

15. Damodaran A., Malátni A., Patil N., Shah N., Suryavansihi, Marathe S. (2002): Therapeutic potential of yoga practices in modifying cardiovascular risk profile in middle aged men and women. J. Assoc. Physicians. India. 50: 633-640

16. Čajka V., Sovová E., Pastucha D. (2010): Vliv cvičení jógy na rizikové faktory kardiovaskulárních onemocnění. Prakt. Lék. 90: 715-717

17. Pastucha D., Talafa V., Malincikova J., Cihalik C., Hyjanek J., Horakova D., Janout V. (2010): Obesity, hypertension and insulin resistance in Childhood - a pilot study. Biomed Pap. Med. Fac. Univ. Palacky. Olomouc. Czech. Repub. 154: 77-82

18. Horakova D., Stejskal D., Pastucha D., Muchova L., Janout V. (2010): Potential markers of insuline resistance in healthy vs obese and overweight subjects. Biomed. Pap. Med. Fac. Univ. Palacky. Olomouc. Czech. Repub. 154: 245-250

Acknowledgement: The study was supported by the grant NT 11098-4/2010 and Infrastructural part of this project (Institute of Molecular and Translational Medicine) was supported by the Operational Programme of Research and Development for Innovations (project CZ.1.05/2.1.00/01.0030).

Received: November, 23, 2011

Accepted: December, 3, 2011 